\title{
Axon Initial Segment-Associated Microglia
}

\author{
Kelli Baalman, ${ }^{1}$ Miguel A. Marin, ${ }^{1}$ Tammy Szu-Yu Ho, ${ }^{2}$ Marlesa Godoy, ${ }^{1}$ Leela Cherian, ${ }^{3}$ Claudia Robertson,,${ }^{1,3}$ \\ and Matthew N. Rasband ${ }^{1,2}$ \\ ${ }^{1}$ Department of Neuroscience, ${ }^{2}$ Program in Developmental Biology, and ${ }^{3}$ Department of Neurosurgery, Baylor College of Medicine, Houston, Texas 77030
}

\begin{abstract}
Microglia are the brain's resident immune cells and function as the main defense against pathogens or injury. However, in the absence of disease, microglia have other functions in the normal brain. For example, previous studies showed that microglia contribute to circuit refinement and synaptic plasticity in the developing and adult brain, respectively. Thus, microglia actively participate in regulating neuronal excitability and function. Here, we report that in the cortex, but not other brain regions, a subset of microglia extend a single process that specifically associates and overlaps with the axon initial segment (AIS), the site where action potentials are generated. Similar associations were not observed with dendrites or distal axons. Microglia-AIS interactions appear early in development, persist throughout adulthood, and are conserved across species including mice, rats, and primates. However, these interactions are lost after microglial activation following brain injury, suggesting that such interactions may be part of healthy brain function. Loss of microglial CX3CR1 receptors, or the specialized extracellular matrix surrounding the AIS, did not disrupt the interaction. However, loss of AIS proteins by the neuron-specific deletion of the master AIS scaffold AnkyrinG disrupted microglia-AIS interactions. These results reveal a unique population of microglia that specifically interact with the AIS in the adult cortex.
\end{abstract}

Key words: axon; axon initial segment; brain injury; glia; ion channel; microglia

\section{Introduction}

Microglia are the resident immune cells of the CNS, and their roles in response to disease and injury have been studied extensively (Kettenmann and Ransom, 2005; Hanisch and Kettenmann, 2007). For example, after injury, microglia undergo dramatic morphological and biochemical changes aimed at protecting the nervous system, including migrating to and barricading the injured site, releasing proinflammatory cytokines, and phagocytosing cellular debris (Kreutzberg, 1996; Hanisch and Kettenmann, 2007; Ransohoff and Perry, 2009). However, injury and disease are typically rare events in the lifetime of a brain. Thus, the functions of microglia in the uninjured and developing brain have also been of interest to neuroscientists. Indeed, it is now generally appreciated that "resting" microglia are anything but resting, and these cells do not simply wait for an insult to the nervous system to be biologically active. Instead, microglia are recognized as important contributors to brain development, homeostasis, plasticity, and function.

Live imaging studies of microglia in the uninjured brain show that although microglial cell bodies are stationary, their processes are constantly extending and retracting to surveil the surround-

Received Sept. 8, 2014; revised Dec. 2, 2014; accepted Dec. 22, 2014.

Author contributions: K.B. and M.N.R. designed research; K.B., M.A.M., T.S.-Y.H., M.G., and L.C. performed research; C.R. contributed unpublished reagents/analytic tools; K.B., M.A.M., and M.N.R. analyzed data; K.B. and M.N.R. wrote the paper.

This work was supported by NIH Grants NS044916 and NS069688 and Department of Defense Grants W81XWH08-2-0132 and W81XWH-08-2-0145. We thank Yanhong Liu for technical assistance and Drs. Andreas Tolias and Kimberley Tolias for providing mice and other reagents.

Correspondence should be addressed to Dr. Matthew N. Rasband, Department of Neuroscience, Baylor College of Medicine, 1 Baylor Plaza, Houston, TX 77030. E-mail: Rasband@bcm.edu.

DOI:10.1523/JNEUROSCI.3751-14.2015

Copyright $\odot 2015$ the authors $\quad 0270-6474 / 15 / 352283-10 \$ 15.00 / 0$ ing environment (Nimmerjahn et al., 2005). Process motility can be altered by sensory experience, ATP, or neurotransmitters (Davalos et al., 2005; Tremblay et al., 2010; Fontainhas et al., 2011). Correspondingly, microglia in the zebrafish optic tectum preferentially contact highly active neurons. After contact, these neurons become less responsive to stimuli and have decreased spontaneous activity (Li et al., 2012). In the developing and adult brain, microglia contact synapses in an activity-dependent manner and prune some synapses by engulfment (Wake et al., 2009; Tremblay et al., 2010; Paolicelli et al., 2011; Schafer et al., 2012). Loss of microglia causes deficits in motor and memory tasks and impaired motor learning-dependent synaptic plasticity (Parkhurst et al., 2013). Furthermore, mice with fractalkine receptor CX3CR1deficient microglia have impaired synaptic pruning, reduced functional connectivity, and abnormal social and grooming behavior (Paolicelli et al., 2011; Zhan et al., 2014). Although increasing evidence supports the conclusion that microglia modulate neuronal activity, the mechanisms remain poorly defined. Besides these diverse functions, accumulating evidence also suggests that microglia are not a homogeneous population of surveilling cells, but rather that their density, sensitivity to neurotransmitters or neurohormones, and morphology also vary across brain regions (Lawson et al., 1990; Hanisch, 2013; Gertig et al., 2014; Pannell et al., 2014).

The axon initial segment (AIS) is responsible for action potential initiation and is a major regulator of neuronal excitability (Kole and Stuart, 2012). While investigating the response of the AIS to nervous system injury, we serendipitously discovered a subpopulation of microglia that specifically align and interact with the AIS. These associations are seen in the normal brain, and when microglia are activated by injury, they are significantly less likely to occur. Loss of the AIS by deletion of its master scaffold- 
ing protein AnkyrinG (AnkG) leads to a significant decrease in the frequency of interactions. Thus, we propose that AISassociated microglia constitute a unique and previously unrecognized population of cells that may influence neuronal excitability.

\section{Materials and Methods}

Animals. Thy1-YFP and Ai9;Viaat-Cre mouse brains were gifts from Drs. Kimberley Tolias and Andreas Tolias, respectively (Baylor College of Medicine, Houston, TX). AnkG ${ }^{\mathrm{f} / \mathrm{fl}}$ mice were described previously (Ho et al., 2014). CX3CR1 ${ }^{\mathrm{GFP}}$ mice were purchased from The Jackson Laboratory. Brevican/Versican $(\mathrm{BcVc})$-deficient mice were described previously (Susuki et al., 2013). Sprague Dawley rats were purchased from Harlan Laboratories and used for controlled cortical impact (CCI) experiments. For all other experiments, C57BL/6 mice were used. Animals were housed at Baylor College of Medicine with access to food and drink ad libitum. Prefrontal cortex from an adult male rhesus monkey (Macaca mulatta) was provided by Dr. Andreas Tolias (Baylor College of Medicine). All surgical and experimental procedures were conducted in accordance with protocols approved by the Baylor College of Medicine Institutional Animal Care and Use Committee and the NIH Guide for the Care and Use of Laboratory Animals.

Brain injury. Mild traumatic brain injury (TBI) was induced using a CCI device as described previously (Robertson et al., 2013). A pneumatic impactor device was set to $35 \mathrm{psi}$, giving an impact velocity of $3 \mathrm{~m} / \mathrm{s}$, and induced a $2.5 \mathrm{~mm}$ deformation of the brain.

In utero electroporation. The in utero electroporation was described previously (Hedstrom et al., 2007). The pCAG-Cre-IRES-EGFP plasmid was a gift from Dr. Franck Polleux (Columbia University, New York) and was introduced into mouse embryos at E14 in $A n k G^{\text {fl/fl }}$ mice or control mice. Electroporated mice were killed at P30 for immunostaining and analysis.

Immunostaining. Immunostaining was performed on $35 \mu \mathrm{m}$ mounted brain sections as described previously (Baalman et al., 2013). Briefly, animals were killed with an overdose of isoflurane. Brains were rapidly removed and placed in $4 \% \mathrm{PFA}$ for $1 \mathrm{~h}$ at $4^{\circ} \mathrm{C}$ and then transferred to $20 \%$ sucrose in $0.1 \mathrm{M} \mathrm{PB}$ and left overnight at $4^{\circ} \mathrm{C}$. Brains were sectioned at 35 $\mu \mathrm{m}$ on a freezing stage microtome, and sections were placed on gelatincoated coverslips. Blocking was done with $0.1 \mathrm{M} \mathrm{PB}, 0.3 \%$ Triton X-100, and $10 \%$ goat serum (PBTGS) for $1 \mathrm{~h}$ at room temperature. Primary antibodies were diluted in PBTGS and left overnight at room temperature. After three washes with PBTGS, secondary antibodies were diluted in PBTGS and left at room temperature for $2 \mathrm{~h}$. After three washes, slides were air dried and mounted for visualization using a fluorescence microscope.

Antibodies. Anti-AnkG (N106/36), anti-FGF14 (N56/21), and antiNav1.6 (K87A/10) mouse monoclonal antibodies were purchased from NeuroMab. Affinity-purified rabbit polyclonal antibodies against $\beta$ IV spectrin were described previously (Yang et al., 2004). NeuN was purchased from Millipore (MAB377). Anti-GFP was purchased from Nacali Teque (GF090R). Hoechst was purchased from Invitrogen (H3570). Anti-Iba1 was purchased from Wako Chemicals (019-19741). CD11b was purchased from AbD Serotec (MCA711). All fluorescent secondary antibodies were purchased from Invitrogen and Jackson ImmunoResearch.

Imaging and analysis. Imaging was performed on a Zeiss Observer Z1 microscope using AxioVision and Zen software. For all quantification, $20 \times(0.8$ numerical aperture $) z$-stacks were taken. Automated AIS quantification was described previously (Baalman et al., 2013). All other image analysis was performed using ImageJ. Brain regions [primary motor cortex (M1), primary visual cortex (V1), primary somatosensory cortex barrel field (S1BF), thalamus, and striatum] were identified using The Rat Brain in Stereotaxic Coordinates (Paxinos and Watson, 2007). For NeuN analysis, three animals were used, two brain sections per animal, and $1220 \times$ fields of view (FOVs) per section (6 FOVs per hemisphere). For Thy1 analysis, three animals were used, two brain sections per animal, and 8 FOVs per section. For the developmental studies and adult analysis, three animals were used per time point, two brain sections per animal, and 8-12 FOVs per section per brain region. For the Ai9; Viaat-
Cre brains, four animals were used, one brain section per animal, and 12 FOVs per section (6 FOVs per hemisphere). For CX3CR1 GFP/GFP and Brevican/Versican-deficient brains, three mice were used, two brain sections per animal, and 12 FOVs per section (6 FOVs per hemisphere). For the CCI studies, three rats were used per time point, two brain sections per animal, 6 FOVs per hemisphere (ipsilateral or contralateral). For a microglia process to be counted as being associated with an AIS, it had to have a process and/or cell body that followed at least $50 \%$ of the length of the AIS. In all experiments, $n$ equals the number of animals.

Statistical analyses. All statistical analyses were performed using GraphPad Prism software. For two-group comparisons, Student's $t$ test was used. For multigroup comparisons, one-way ANOVA was used with Bonferroni's post hoc test. For the CCI data, a two-way ANOVA was used with Bonferroni's post hoc test. Data are presented as mean \pm SEM unless noted otherwise, and $p$ values $<0.05$ were considered significant.

\section{Results}

A subset of "satellite" microglia associate with the AIS

A variety of nervous system injuries can dismantle or remodel the AIS (Schafer et al., 2009; Kuba et al., 2010; Baalman et al., 2013; Hinman et al., 2013). Since microglia are activated by nervous system injury, we reasoned that they might also disrupt the AIS. To determine the location of microglia in the intact, uninjured brain relative to the AIS, we labeled brain sections from CX3CR1 ${ }^{+/ G F P}$ mice (GFP-labeled microglia; Jung et al., 2000) with anti-NeuN to visualize neuronal cell bodies and anti-AnkG to identify the AIS. We found that in the adult mouse cortex, a subset of microglia $(15.69 \pm 0.44 \%)$ were intimately associated with the neuronal cell body (Fig. $1 A$ ); these microglia have previously been called perineuronal satellite microglia and may provide trophic or metabolic support to highly active neurons, or be involved in synaptic remodeling of those cells they contact (Kettenmann and Ransom, 2005). By contrast, only $2.84 \pm$ $0.13 \%$ of cortical neurons were found to have satellite microglia. Although satellite microglia were detected on all parts of the soma $(20.15 \pm 2.12 \%$ and $18.01 \pm 3.37 \%$ contacting apical and lateral regions, respectively), they were preferentially found on the axonal side (61.84 $\pm 4.96 \%)$. Remarkably, among those satellite microglia found on the axonal side, $47 \%$ $(28.78 \pm 0.26 \%$ of all satellite microglia) had a process that appeared to interact with and extend along at least half of the AIS (Fig. $1 B$ ). Immunostaining with a variety of markers for the AIS (FGF14, AnkG, Nav1.6, and $\beta$ IV spectrin) and microglia (Iba1 and Cd11b) confirmed overlapping immunoreactivities (Fig. $1 C-F$ ). Furthermore, AIS-microglia associations are present in multiple species, including mice (Fig. $1 B-F, I, J$ ), rats (Rattus norvegicus; Fig. $1 K$ ), and nonhuman primates (Macaca mulatta; Fig. $1 L$ ).

Using Thy1-YFP mice that have constitutively labeled layer 5 pyramidal neurons, we found that microglia associated with the apical dendrite in only $0.14 \pm 0.07 \%$ of YFP + neurons $(n=3$ animals, 905 neurons), whereas $4.35 \pm 0.95 \%$ of YFP + neurons had microglia aligned with their AIS (Fig. $1 G-I$ ). Close examination of AIS-associated microglia revealed that their cell bodies could be located at a variety of positions along the AIS (Fig. $2 A, F)$ : at the start of the AIS adjacent to the neuronal cell body (Fig. 2B), at the middle of the AIS (C), or at the end of the AIS (D). We also found examples of overlapping AIS and microglia processes where the cell body did not contact the AIS (Fig. $2 E)$. Together, these results reveal a unique and previously unrecognized group of Axon initial segment associated (AXIS) microglia.

Although microglia enter the mouse brain at about embryonic day 9.5 (E9.5; Chan et al., 2007; Ginhoux et al., 2010), 

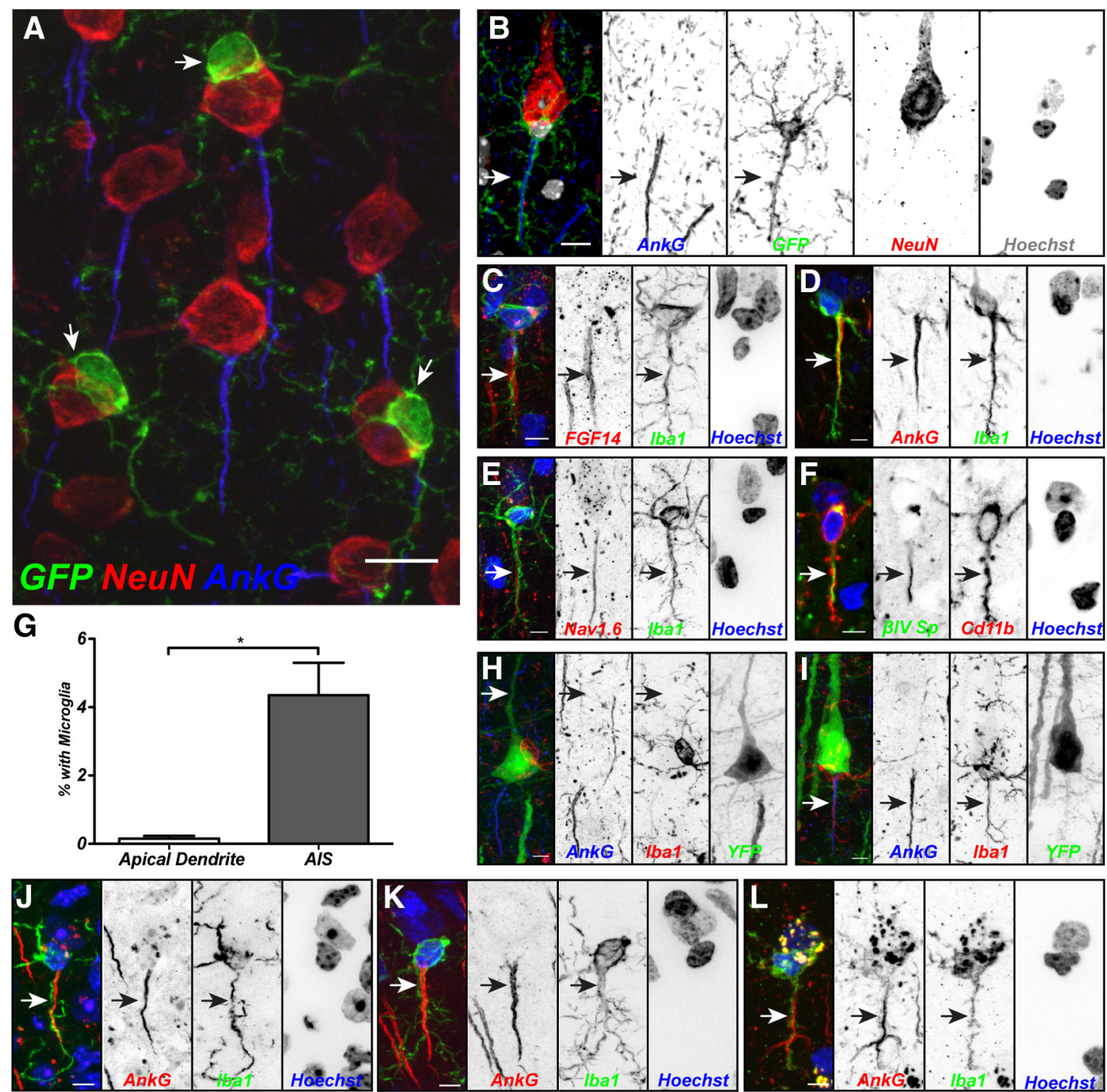

Figure 1. A subset of satellite microglia interact with the AIS.A, Mouse cortical neurons labeled for NeuN (red) and AnkG (blue) are contacted by perineuronal satellite microglia (arrow; GFP from a $\mathrm{CX} 3 \mathrm{CR} 1^{\mathrm{GFP} /+}$ mouse). B, A mouse cortical neuron labeled for NeuN (red) and AnkG (blue), and a perineuronal satellite microglia aligned along the AIS (arrow; GFP from a CX3CR1 ${ }^{\text {GFP/+ }}$ mouse). Hoechst labels nuclei (white in the merged image). C, Immunostaining for FGF14 to label the AIS (red, arrow), Iba1 to label microglia (green), and Hoechst to label nuclei (blue). $\boldsymbol{D}$, Immunostaining for AnkG to label the AIS (red, arrow), Iba1 to label microglia (green), and Hoechst to label nuclei (blue). $\boldsymbol{E}$, Immunostaining for Nav1.6 to label the AIS (red, arrow), Iba1 to label microglia (green), and Hoechst to label nuclei (blue). $\boldsymbol{F}$, Immunostaining for $\beta$ IV spectrin to label the AIS (green, arrow), Cd11b to label microglia (red), and Hoechst to label nuclei (blue). $\mathbf{G}$, Quantification of associations between microglia and the apical dendrite or AIS in Thy $1+$ layer 5 pyramidal cells $(n=3,904$ cells). $\boldsymbol{H}$, Satellite microglia do not associate with the apical dendrite (arrow) in layer 5 cells. I, Example of overlapping AIS (arrow) and microglial branch in Thy1+ cell. $\boldsymbol{J}-\boldsymbol{L}$, Immunostaining of AIS (AnkG, red), microglia (Iba1, green), and nuclei (Hoechst) in mouse $(\boldsymbol{J})$, rat $(\boldsymbol{K})$, and macaque (L) cortex. Scale bars: $\boldsymbol{A}, 10 \mu \mathrm{m} ; \boldsymbol{B}-\boldsymbol{F}, \boldsymbol{H}-\boldsymbol{L}, 5 \mu \mathrm{m} .{ }^{*} p<0.05$ (unpaired $t$ test with Welch's correction).

they are relatively sparse until postnatal day 7 (P7)-P9, when microglia proliferate and undergo rapid local expansion (Hristova et al., 2010). To determine when AXIS microglia appear, we analyzed cortex from P9, P15, and P30 mice. Although AXIS microglia were found at all time points examined (Fig. $3 A, B$ ), the frequency increased throughout development, and their position at the proximal AIS became more prominent with increasing age (Fig. $2 F$ ). The number of microglia per FOV increased significantly between $\mathrm{P} 9$ and $\mathrm{P} 15$, as microglia rapidly divided to populate the cortex, but the density then decreased by P30 as the size of the brain increased (Fig. 3C). Since nearly all AISs in the cortex are present by P9 (Galiano et al., 2012), we also observed a decrease in the number of AISs per FOV due to the increase in brain size during development (Fig. 3D).
To determine whether there are differences in the number of AXIS microglia among brain regions, we measured their percentages and the percentages of AISs with AXIS microglia in M1, S1BF, V1, thalamus, and striatum in adult mice $(8-12$ weeks old; Fig. $3 E, F)$. We found that the percentage of AXIS microglia is consistent across cortical areas ( $\sim 8 \%$ of microglia are AXIS microglia in the adult cortex), but the thalamus and striatum have significantly fewer AXIS microglia (Fig. 3E), resulting in significantly fewer AISs with associated microglia in these latter brain regions (Fig. $3 F$ ). Furthermore, the cortical areas and striatum had similar numbers of microglia per FOV, whereas the thalamus has significantly fewer microglia per FOV (Fig. $3 G$ ), suggesting that differences in the percentage of AXIS microglia across brain regions do not simply reflect differences in the number of microglia found in those brain regions. On the other hand, the fre- 

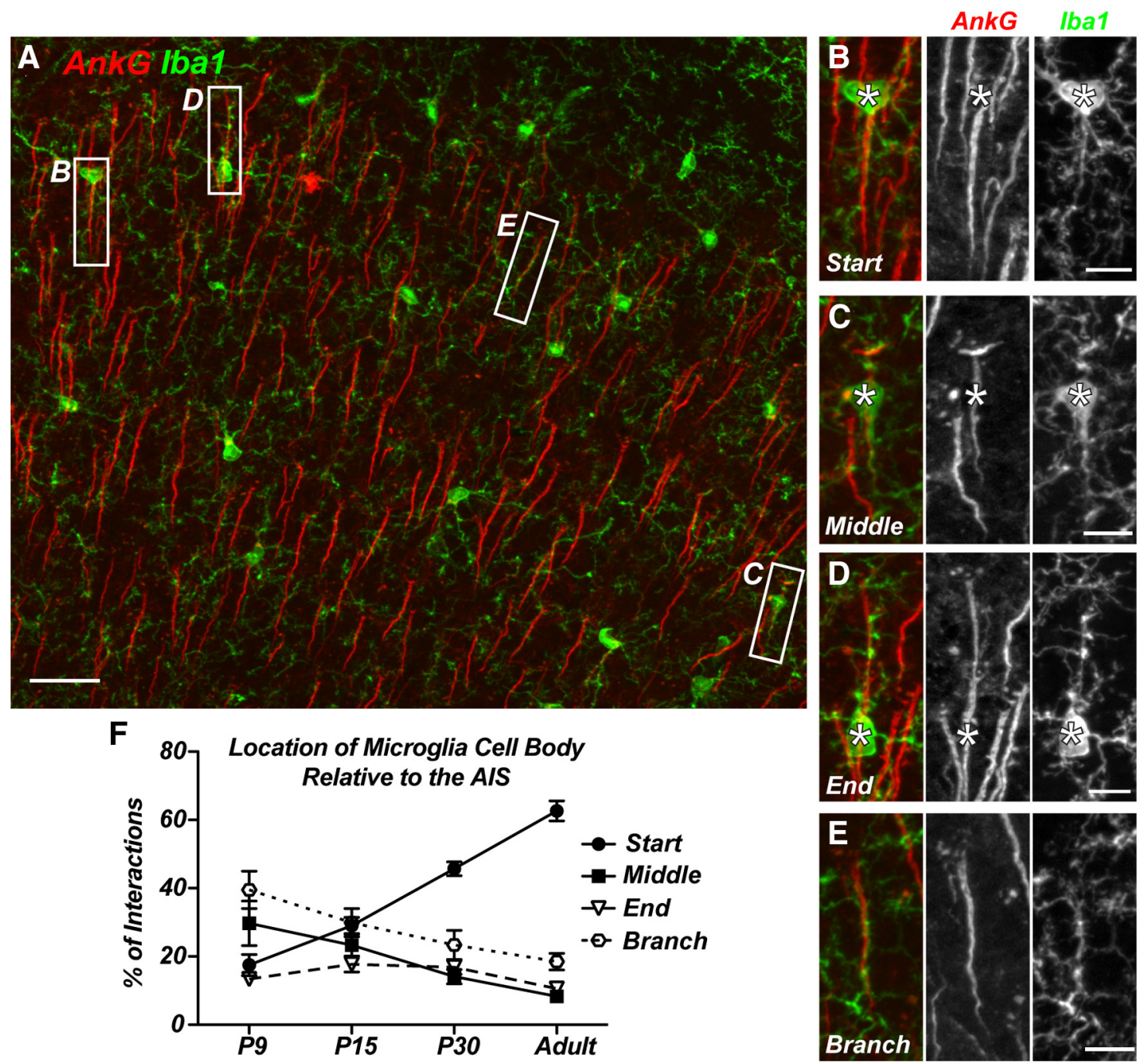

Figure 2. AIS-associated microglial cell bodies are preferentially located at the start of the AIS. A, AnkG-labeled cortical AIS (red) and GFP + microglia from a CX3CR1 ${ }^{+/ 6 F P}$ mouse show multiple examples of AIS-microglia overlaps (white boxes). $\boldsymbol{B}-\boldsymbol{D}$, Microglial cell bodies located at the start (B), middle ( $\boldsymbol{C}$, and end (D) of the AIS. $\boldsymbol{E}$, A "branched: microglial cell process associated with the AIS. $F$, Quantification of the location of the AIS-associated microglial cell body relative to the AIS at P9, P15, and P30 and in the adult. P9, P15, and P30 data are from M1 only; adult data include regions $\mathrm{M1}$, S1BF, and V1. Scale bars: $\boldsymbol{A}, 25 \mu \mathrm{m} ; \boldsymbol{B}-\boldsymbol{E}, 8 \mu \mathrm{m}$.

quency of interactions may reflect the number of AISs in a brain region that can be contacted since the percentage of AXIS microglia most closely parallels the number of AISs in a given brain region (Fig. 3H). Together, these observations reveal developmental and brain-region-specific differences in the number of AXIS microglia.

\section{Activated microglia do not associate with the AIS}

What do AXIS microglia do? In the normal brain, AXIS microglia are morphologically indistinguishable from other microglia. Nevertheless, in many instances, the longest process of AXIS microglia overlapped with the AIS (Fig. 1D), but a single long microglial process was not predictive of AIS overlap (data not shown). Microglia have very plastic morphologies, and virtually any insult to the brain can cause microglia to become activated (Nimmerjahn et al., 2005; Hanisch and Kettenmann, 2007). Activated microglia have a variety of morphological responses, including increased soma size, retraction and thickening of processes, and eventually loss of all processes (Hanisch and Kettenmann, 2007; Ransohoff and Perry, 2009). To determine whether the number of AXIS microglia increases in response to brain injury and whether microglia contribute to AIS disruption or remodeling, we examined AXIS microglia in the CCI model of TBI. Using the impactor, we induced a mild TBI as described previously (Robertson et al., 2013). Robust morphological changes occurred in microglia on the ipsilateral (injured) side of the brain as early as $3 \mathrm{~h}$ after injury, accompanied by an increase in Ibal expression that persisted for $72 \mathrm{~h}$ after injury (Fig. $4 A$ ). At 3,24 , and $72 \mathrm{~h}$ after injury, we found significantly fewer AXIS microglia on the injured side of the brain (Fig. 4B). Furthermore, the number of AIS with AXIS microglia was also reduced (Fig. $4 B)$. We did not observe an increase in the total number of microglia on the ipsilateral side of the brain until $72 \mathrm{~h}$ after injury, although we cannot exclude the possibility that these cells correspond to infiltrating macrophages in response to the injury, and we observed no reduction in the number of AISs (Fig. 4C). Thus, in contrast to our original expectation, microglia do not preferentially interact with the AIS after injury, and they do not contribute to AIS dismantling. Instead, these data suggest that AXIS microglia are a class of surveilling microglia that play roles primarily in normal brain function. 


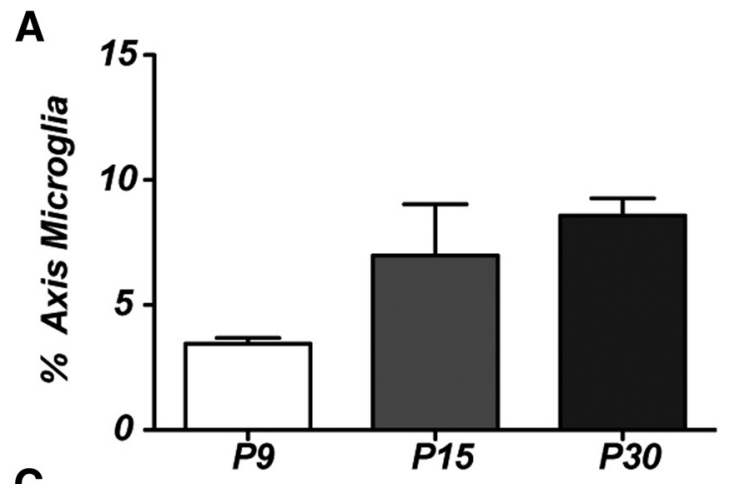

C
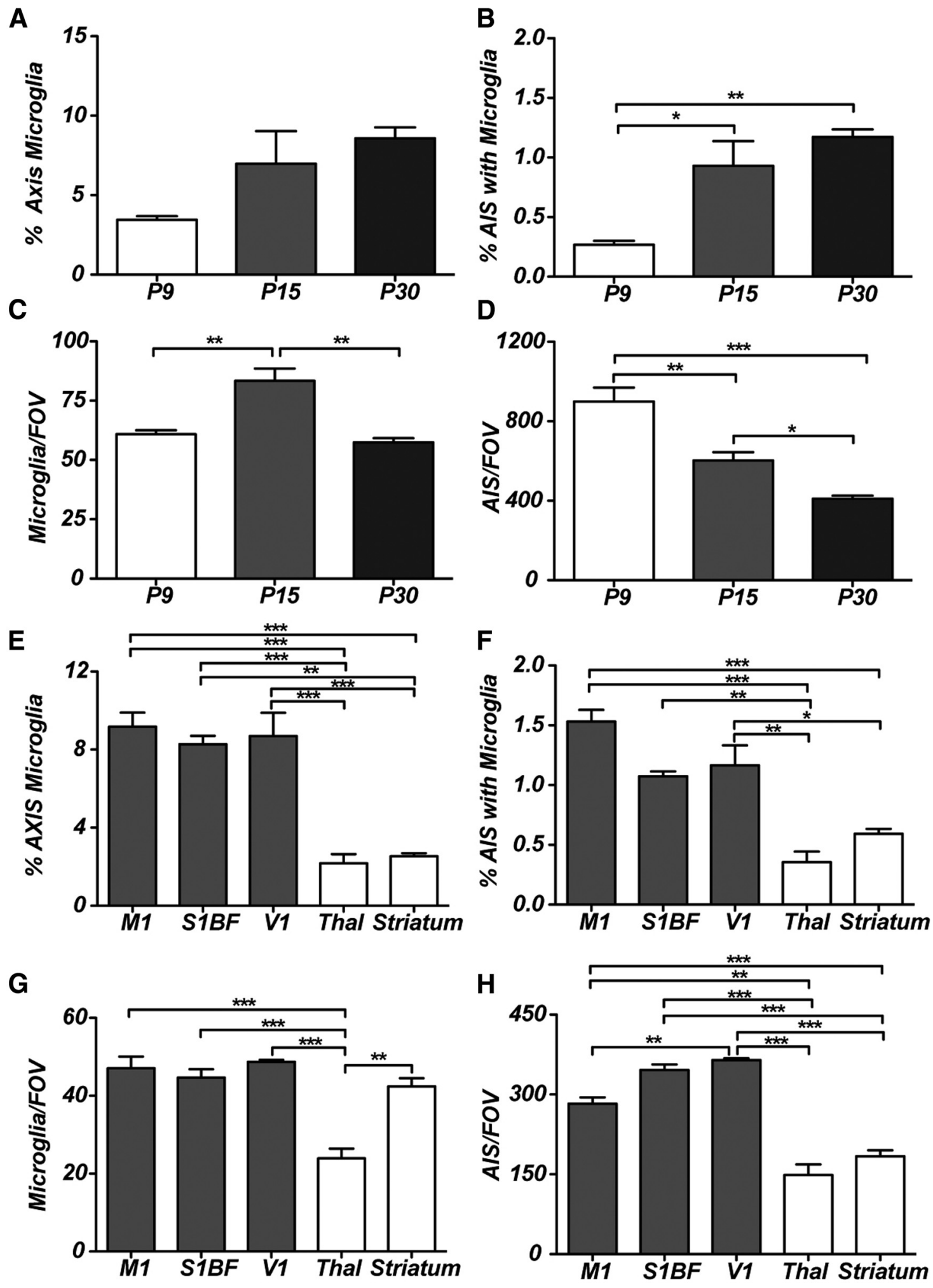

Figure 3. The frequency and distribution of AXIS microglia. $\boldsymbol{A}$, The percentage of AXIS microglia as a function of age. $\boldsymbol{B}$, The percentage of AISs with an associated microglia as a function of age. $\boldsymbol{C}$, The number of microglia per FOV changes as a function of age. $\boldsymbol{D}$, The number of AISs per FOV decreases as the size of the brain increases during development. $\boldsymbol{E}$, $\boldsymbol{F}$, The percentage of AXIS microglia in different brain regions: M1, S1BF, V1, thalamus (Thal), and striatum. $\mathbf{G}, \boldsymbol{H}$, The numbers of microglia per FOV and AISs per FOV in different brain regions. ${ }^{*} p<0.05$; ${ }^{* *} p<0.01 ;{ }^{* * *} p<0.001$ (one-way ANOVA with Bonferroni's multiple comparison test). $n=3$ animals in all experiments.

AXIS microglia preferentially associate with excitatory neurons

Perineuronal satellite microglia have been suggested to provide trophic or metabolic support to highly active neurons, or to be involved in synaptic remodeling (Kettenmann and Ransom, 2005). Alternatively, AXIS microglia may preferentially associate with functionally distinct types of neurons. To test this possibility, we used Viaat-cre;Ai9 reporter mice, which express tdTomato 
A
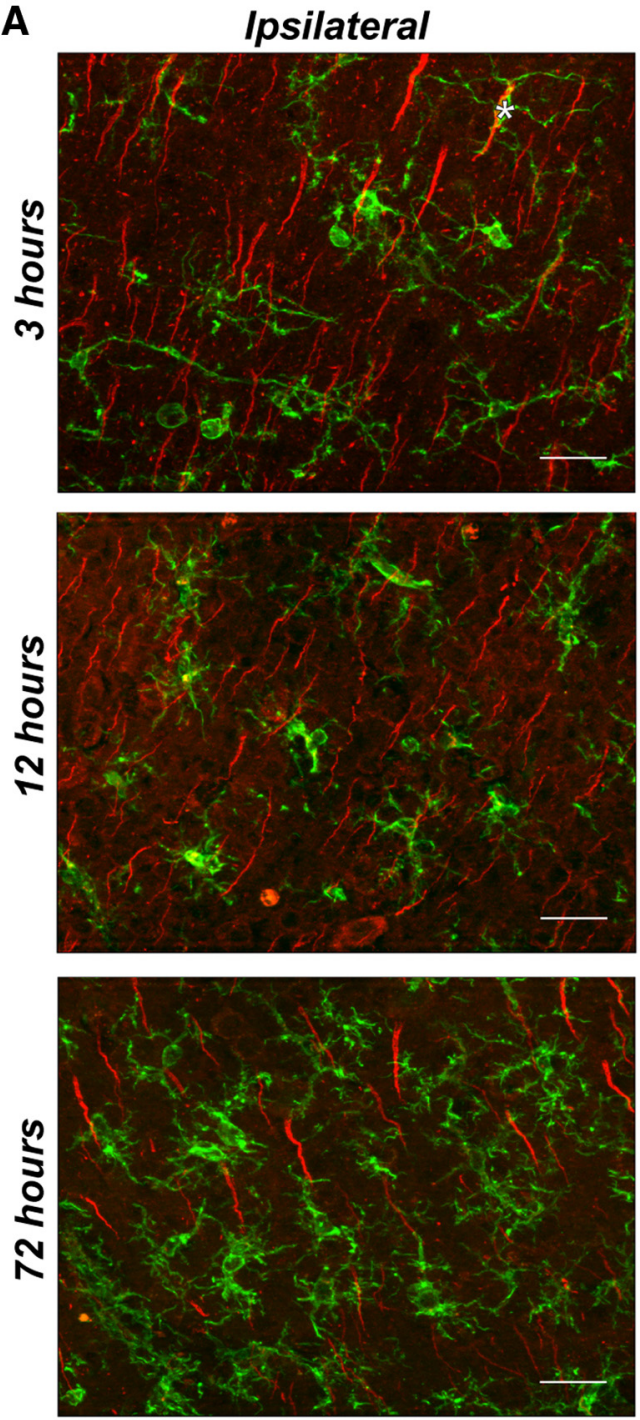

B

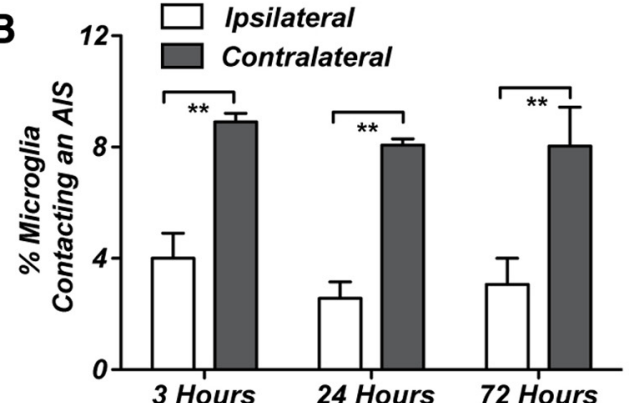

C

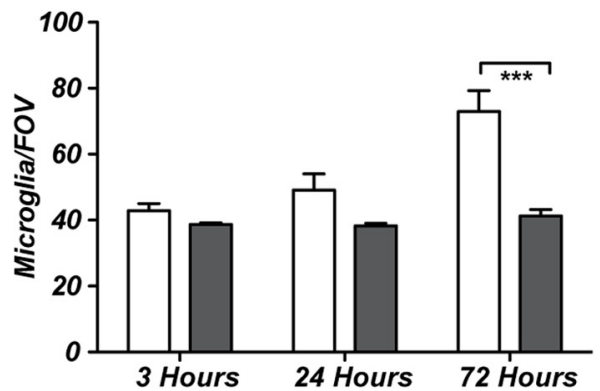

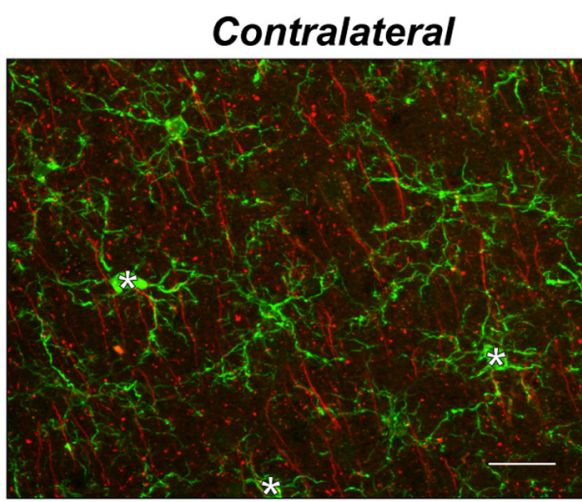
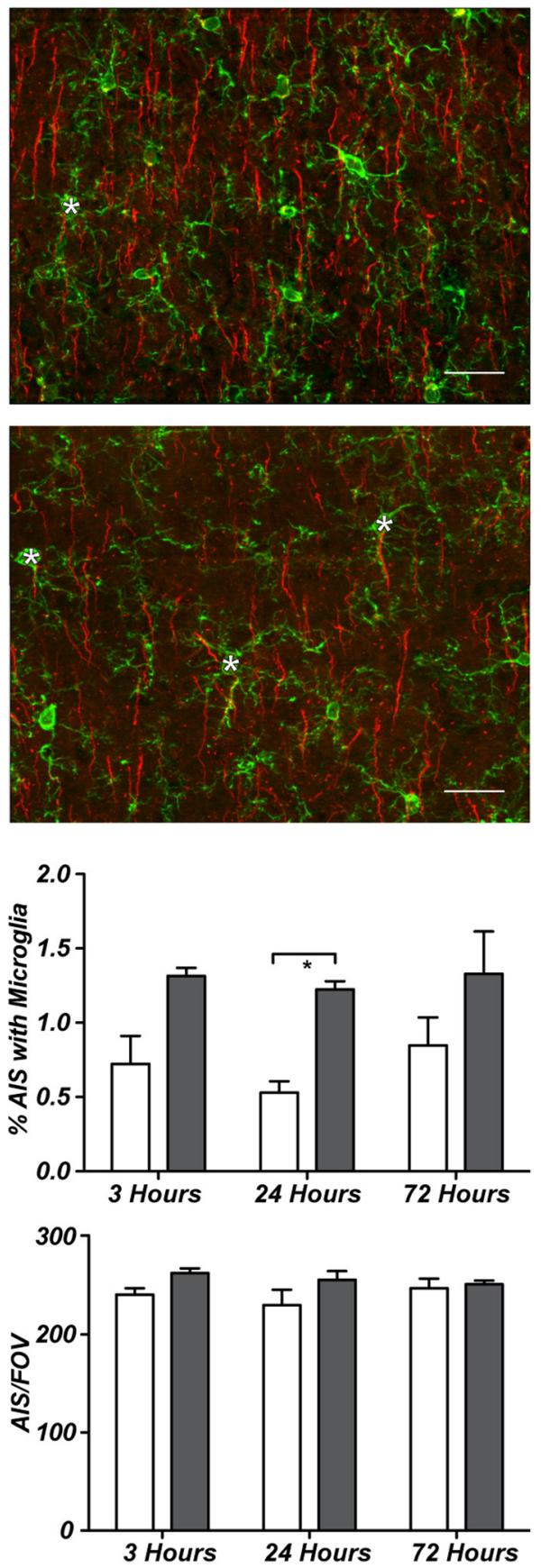

Figure 4. Activated microglia do not associate with the AIS. $\boldsymbol{A}$, Representative images from 3,12 , and $72 \mathrm{~h}$ after injury on both the injured and contralateral sides of the brain. Asterisks indicate AXIS microglia (green, anti-Iba1); AISs are labeled by anti-AnkG (red). B, The percentage of AXIS microglia at 3, 24, and $72 \mathrm{~h}$ after injury. $\boldsymbol{C}$, The number of microglia is significantly higher $72 \mathrm{~h}$ after injury, whereas the number of AISs does not change. Scale bars, $25 \mu \mathrm{m} .{ }^{*} p<0.05$; ${ }^{* *} p<0.01 ;{ }^{* * *} p<0.001$ (two-way ANOVA with Bonferroni multiple comparison test), $n=3$ animals per time point. 

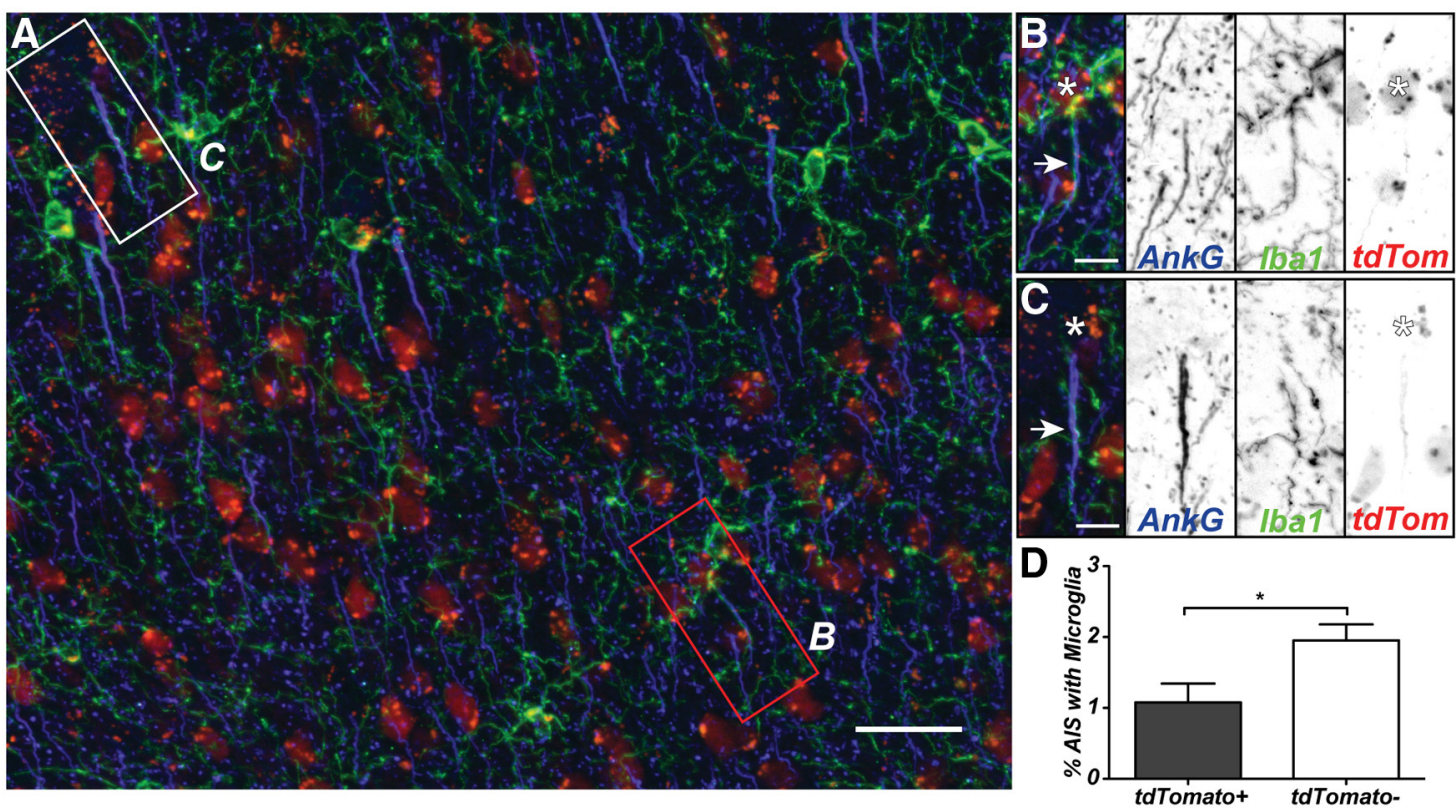

Figure 5. AXIS microglia preferentially interact with non-GABAergic neurons. $A$, Cortex showing GABAergic neurons (tdTomato, red), AISs (anti-AnkG, blue), and microglia (anti-lba1, green). $\boldsymbol{B}$, C, Example of a microglia/AIS interaction in a tdTomato + cell (B) and a tdTomato - cell (C). Arrows show overlapping processes, and the asterisk marks the neuronal cell body. $\boldsymbol{D}$, The percentage of tdTomato + and tdTomato - neurons with AXIS microglia ( $n=4$ mice). Scale bars: $A, 25 \mu \mathrm{m} ; \boldsymbol{B}, \boldsymbol{C}, 5 \mu \mathrm{m} .{ }^{*} p<0.05$ (unpaired Student's $t$ test).

specifically in GABAergic neurons (Fig. 5A; Chao et al., 2010). Consistent with previous reports, we found $15.34 \pm 2.74 \%$ of neurons in the adult cortex (M1) to be labeled for tdTomato (Merchant et al., 2012). Of 1750 tdTomato + cells $(n=4$ animals), $1.08 \pm 0.26 \%$ had AXIS microglia (Fig. $5 B$ ). This was significantly fewer than for tdTomato - neurons, of which $1.95 \pm$ $0.23 \%$ had AXIS microglia (Fig. $5 C, D$ ). In Thyl-YFP mice, AXIS microglia were found at $4.35 \pm 0.95 \%$ of layer 5 pyramidal neurons (Fig. $1 G, I$ ), compared to $1.26 \pm 0.09 \%$ for all neurons across the cortex. Together, these data suggest that AXIS microglia prefer specific neuronal populations.

\section{AXIS microglia require an intact AIS}

How do AXIS microglia associate with the AIS, and are AIS proteins required for this interaction? Since little is known about the molecules mediating interactions between microglia and neurons, we tested whether CX3CR1 ${ }^{\mathrm{GFP} / \mathrm{GFP}}$ mice (fractalkine receptor knock-out), have reduced numbers of AXIS microglia. CX3CR1 signaling was shown previously to be involved in neuron-microglia communication, synaptic pruning by microglia, microglia migration, hippocampal neurogenesis, and cognitive function (Sierra et al., 2010; Bachstetter et al., 2011; Paolicelli et al., 2011; Rogers et al., 2011; Hoshiko et al., 2012). Compared with CX3CR $1^{+/ G F P}$ mice, we found no difference in the percentage of AXIS microglia or AISs contacted by microglia, or total number of microglia or AISs (Fig. $6 A, C-F$ ). Thus, CX3CR1 signaling is not required for AXIS microglia.

AISs are ensheathed by a specialized extracellular matrix (ECM) consisting of the chondroitin sulfate proteoglycans Brevican and Versican (Hedstrom et al., 2007; Susuki et al., 2013). To determine whether AXIS microglia interact with this AIS ECM, we generated mice lacking both Brevican and Versican (BcVc DKO; Susuki et al., 2013). However, we found no difference in the percentage of AXIS microglia or AISs contacted by microglia, or the total number of microglia or AISs (Fig. $6 B, C-F$ ). Thus, the AIS ECM is not required for AXIS microglia.
Finally, to determine whether AXIS microglia require an intact AIS, we eliminated AnkG expression from individual cortical neurons in vivo. AIS assembly and the clustering of all AIS proteins depends on AnkG (Hedstrom et al., 2007). To do this, we performed in utero electroporation at embryonic day 14 to introduce Cre-GFP into AnkG ${ }^{\mathrm{fl} / \mathrm{fl}}$ mice (AnkG KO) or control $\left(\mathrm{AnkG}^{+/+}\right)$mice. We confirmed that $A n \mathrm{AG}^{\mathrm{fl} / \mathrm{fl}}$ neurons expressing Cre-GFP had no AnkG-labeled AISs (Fig. 6G,H, arrow). We counted the number of AXIS microglia in electroporated neurons from P30 mice and saw a significant decrease in the frequency of interactions in AnkG KO neurons compared to control animals electroporated with the same construct (Fig. 6I, arrow, $J$; $n=1011 \mathrm{GFP}+$ electroporated neurons from three $\mathrm{AnkG}^{\mathrm{fl} / \mathrm{fl}}$ mice and 1014 GFP + electroporated neurons from four control mice). In contrast, we saw no decrease in the percentage of perineuronal satellite microglia (Fig. $6 \mathrm{~K}$ ). These results strongly suggest that specific AIS proteins mediate neuron-microglia interactions and define AXIS microglia.

\section{Discussion}

To understand how the brain works will require a detailed understanding of its cellular constituents, their functions, and their interactions. Cells in the brain have been classified according to their transcriptional profiles, the unique molecules they express, and their location, excitability, and morphology. Whereas the diversity of neurons is widely appreciated and has been studied for many years, glial diversity is only now being characterized and shown to contribute to nervous system function. For example, it is evident that heterogeneity exists among both astrocytes and microglia, and their properties can even be modulated by stimuli ranging from normal neural activity to injury and disease (Zhang and Barres, 2010; Rusnakova et al., 2013; Gertig and Hanisch, 2014).

The results presented here are the first showing a unique pool of cortical perineuronal satellite microglia that specifically associate with the AIS in the uninjured brain; we have named these cells AXIS microglia. Although we do not know whether AXIS microglia have unique transcriptional or protein expression pro- 
A

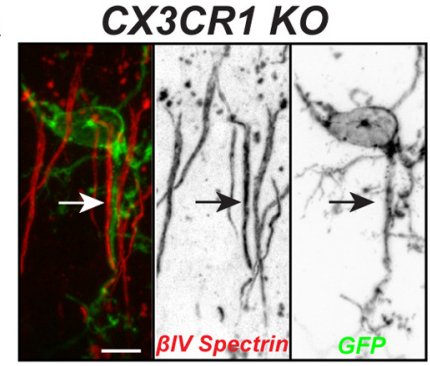

B

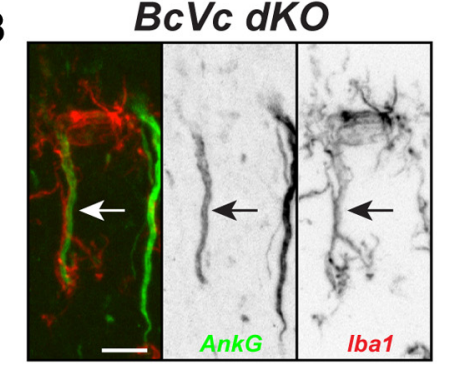

C

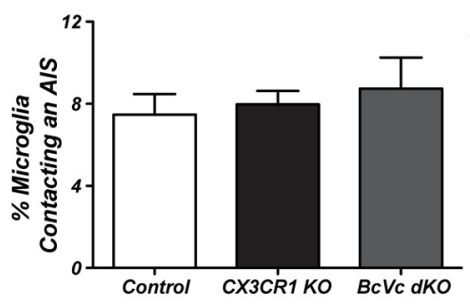

E

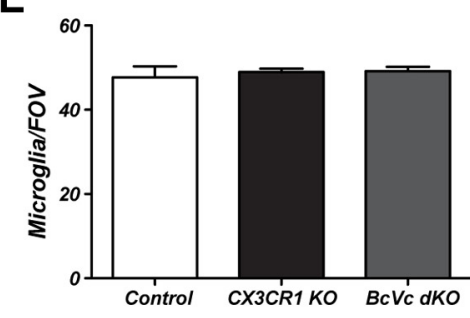

D

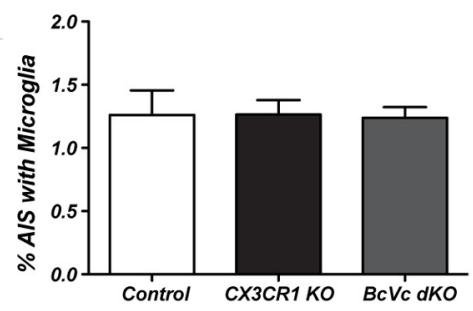

F

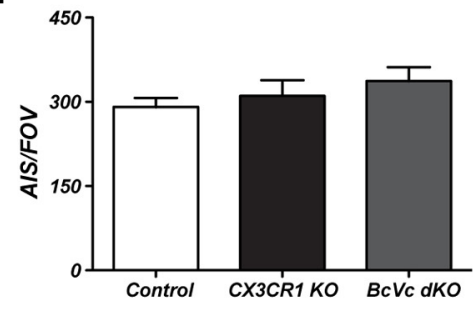

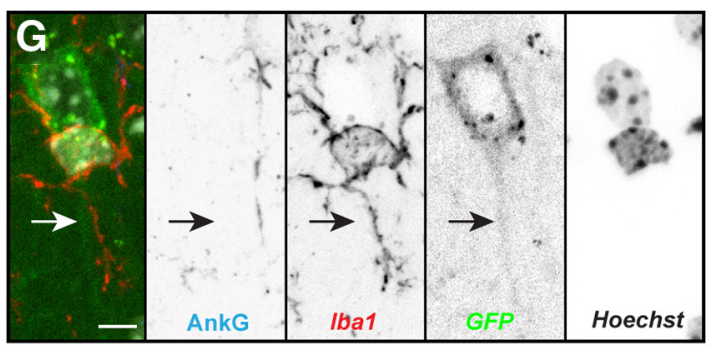
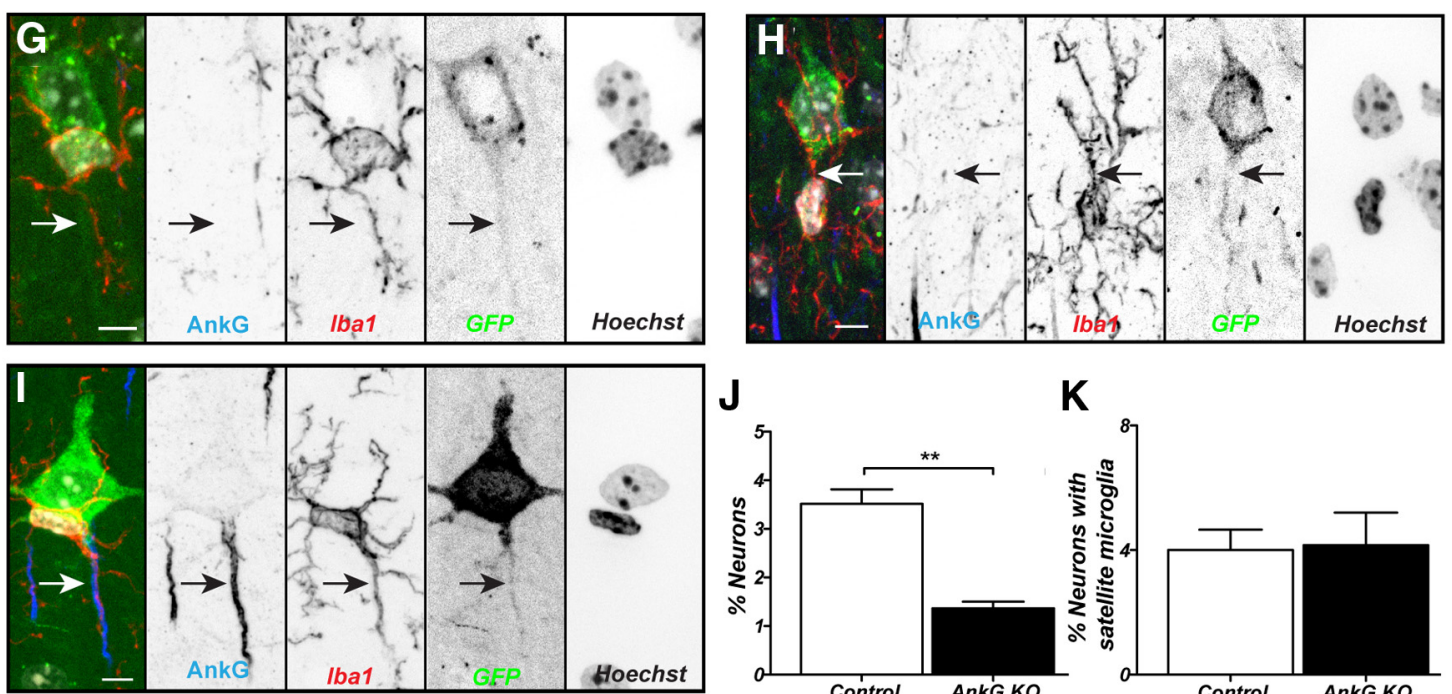

J

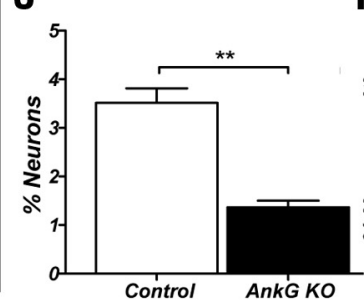

K

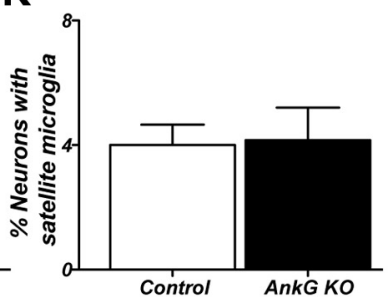

Figure 6. An intact AIS is required for AIS-microglia interactions. $A$, AXIS microglia in a CX3CR1 GFP/GFP (CX3CR1 K0) mouse. The AIS (arrow) is labeled using anti- $\beta$ IV spectrin antibodies (red). $B$, AXIS microglia labeled using Iba1 antibodies (red) in a Brevican - / - ;Versican - / - (BCVC DKO) mouse. The AIS (arrow) is labeled using anti-AnkG antibodies (green). C, D, Neither the percentage of microglia contacting the AIS nor the percentage of AIS with AXIS microglia is different between control, CX3CR1 KO, and BCVC DKO mice. $E$, $F$, Neither the number of microglia per FOV nor the number of AISs per FOV is different between control, CX3CR1 KO, and BCVC DKO mice. G, A perineuronal satellite microglia (Iba1, red) at the start of the axon in a Cre-GFP electroporated, AnkG-deficient neuron. AISs are labeled using anti-AnkG antibodies (blue), and nuclei are labeled by Hoechst (white in the merged image). The axon is indicated by an arrow, and the microglial process does not interact with the axon. $\boldsymbol{H}$, Example of an interaction in a neuron lacking AnkG with the microglia in the middle of the AIS. The axon is indicated by an arrow. $\boldsymbol{I}$, Example of a control GFP + cell (green) with an AXIS microglia labeled using anti-lba1 antibodies (red). The AIS is labeled using antibodies against AnkG (blue), and the nuclei of the neuron and AXIS microglia are labeled using Hoechst (white in the merged image). $\boldsymbol{J}, \boldsymbol{K}$, The percentage of control and AnkG-deficient (AnkG K0) neurons with an AXIS microglia (J) or satellite microglia (K). Scale bars: $\boldsymbol{A}, \boldsymbol{B}, 5 \mu \mathrm{m} ; \boldsymbol{G}-\boldsymbol{I}$, $8 \mu \mathrm{m}$. ${ }^{* *} p<0.01$ (unpaired Student's $t$ test). In $\boldsymbol{A}-\boldsymbol{F}, n=3$ mice per genotype. In $\mathbf{G}-\boldsymbol{K}, n=3$ mice for AnkG K0, with 1011 analyzed, and $n=4$ mice for controls, with 1014 neurons analyzed.

files, the specific association and interaction of AXIS microglia with the AISs of cortical neurons suggests they comprise a distinct population of microglia. However, the response of AXIS microglia to injury shows that as with other microglia in the brain, their phenotype is plastic and they can actively respond to disease or injury. Thus, in addition to the classifiers of cell types listed above, we propose that the connections among cell types and the state of the brain (i.e., disease, activity, etc.) must also be considered when classifying cells in the nervous system.

AXIS microglia comprise $\sim 8 \%$ of the total cortical microglia, but associate with only a small percentage of AISs: $1 \%$ across the entire cortex, but as high as $4 \%$ in layer 5 pyramidal neurons. AXIS microglia preferentially interact with cortical excitatory neurons, but are rarely observed in thalamus, striatum, or cere- bellum. In vivo imaging of microglia suggests that although microglial cell bodies are quite stationary, their processes are extremely motile (Nimmerjahn et al., 2005). Since the majority of AXIS microglial cell bodies are located at the start of the AIS, it will be interesting to determine whether the processes associated with the AIS are also static, or if they are highly motile and only transiently contact the AIS. If the latter is true, the measurement of $1-4 \%$ of AISs being contacted by AXIS microglia may underestimate the total number of AISs sampled. In any case, it is not clear why some neurons have AXIS microglia, whereas most do not.

AXIS microglia may reflect unique properties of the contacted AISs, the AXIS microglial cells, or both. Several cell adhesion molecules (CAMs) and extracellular matrix molecules are en- 
riched at the AIS, including NF186, NrCAM, Caspr2, TAG1, ADAM22, Brevican, and Versican (Hedstrom et al., 2007; Ogawa et al., 2008, 2010; Susuki et al., 2013). The ECM proteins Brevican and Versican are dispensable for AXIS microglia, but future studies will be required to determine whether other known AIS CAMs interact with AXIS microglia. Alternatively, some other unknown AIS CAM may be specific to those neurons contacted by AXIS microglia and mediate the interaction. Loss of AnkG (AnkG is required for all AIS-enriched proteins; Hedstrom et al., 2007) significantly reduced the number of AXIS microglia, confirming that molecules normally restricted to the AIS are important for AXIS microglia and that the interactions described here are not random.

What do AXIS microglia do? AXIS microglia may provide trophic support to neurons to modulate their functions and/or viability, as has been proposed for other satellite microglia (Kettenmann and Ransom, 2005; Ueno et al., 2013). Several cell types in the brain specifically contact and interact with the AIS. Chandelier neurons in the cortex form GABAergic synapses on the AISs of excitatory neurons. These synapses modulate pyramidal neuron output since they provide excitatory or inhibitory drive to the AIS depending on the pyramidal neuron's resting membrane potential (Szabadics et al., 2006; Woodruff et al., 2011). In the cerebellum, GABAergic basket cells innervate Purkinje neuron AISs and form the highly organized cerebellar pinceau. These terminals are enriched with $\mathrm{K}^{+}$channels and have been proposed to modulate Purkinje neuron output, although this conclusion remains controversial (Iwakura et al., 2012). By analogy to chandelier and basket cell neurons, the function of AXIS microglia may be to modulate the excitable properties of the AISs they contact. This could occur through the regulation of local ion concentrations, for example, by buffering $\mathrm{K}^{+}$through inwardly rectifying $\mathrm{K}^{+}$channels found in microglia (Newell and Schlichter, 2005). Alternatively, AXIS microglia may monitor AIS synapses. During development, microglia engulf synaptic material, suggesting that they actively prune synapses and participate in circuit refinement (Paolicelli et al., 2011; Schafer and Stevens, 2013). In the adult brain after disease or injury, microglia can strip synapses from dendrites. We speculate that AXIS microglia may perform similar functions for chandelier neurons at the AIS in the adult, uninjured brain. This function would be consistent with recent studies showing that AIS properties are plastic and can be modified depending on neural activity (Grubb and Burrone, 2010; Kuba et al., 2010; Baalman et al., 2013). In this case, AXIS microglia may alter neuronal activity by removing GABAergic synapses that, depending on the state of the neuron being modified, could increase or decrease AIS excitability. Testing these possibilities will require efficient ways of simultaneously monitoring both AIS properties and AXIS microglia in the intact brain.

In conclusion, we describe AXIS microglia, a subpopulation of microglia that specifically associate with the axon initial segment. Although the functions of these cells are at present enigmatic, our data provide additional support for the concept that microglia are heterogeneous and play diverse roles in the normal adult brain.

\section{References}

Baalman KL, Cotton RJ, Rasband SN, Rasband MN (2013) Blast wave exposure impairs memory and decreases axon initial segment length. J Neurotrauma 30:741-751. CrossRef Medline

Bachstetter AD, Morganti JM, Jernberg J, Schlunk A, Mitchell SH, Brewster KW, Hudson CE, Cole MJ, Harrison JK, Bickford PC, Gemma C (2011)
Fractalkine and CX 3 CR1 regulate hippocampal neurogenesis in adult and aged rats. Neurobiol Aging 32:2030-2044. CrossRef Medline

Chan WY, Kohsaka S, Rezaie P (2007) The origin and cell lineage of microglia: new concepts. Brain Res Rev 53:344-354. CrossRef Medline

Chao HT, Chen H, Samaco RC, Xue M, Chahrour M, Yoo J, Neul JL, Gong S, Lu HC, Heintz N, Ekker M, Rubenstein JL, Noebels JL, Rosenmund C, Zoghbi HY (2010) Dysfunction in GABA signalling mediates autismlike stereotypies and Rett syndrome phenotypes. Nature 468:263-269. CrossRef Medline

Davalos D, Grutzendler J, Yang G, Kim JV, Zuo Y, Jung S, Littman DR, Dustin ML, Gan WB (2005) ATP mediates rapid microglial response to local brain injury in vivo. Nat Neurosci 8:752-758. CrossRef Medline

Fontainhas AM, Wang M, Liang KJ, Chen S, Mettu P, Damani M, Fariss RN, Li W, Wong WT (2011) Microglial morphology and dynamic behavior is regulated by ionotropic glutameric and GABAergic neurotransmission. PLoS One 6:e15973. CrossRef Medline

Galiano MR, Jha S, Ho TS, Zhang C, Ogawa Y, Chang KJ, Stankewich MC, Mohler PJ, Rasband MN (2012) A distal axonal cytoskeleton forms an intra-axonal boundary that controls axon initial segment assembly. Cell 149:1125-1139. CrossRef Medline

Gertig U, Hanisch UK (2014) Microglial diversity by responses and responders. Front Cell Neurosci 8:101. Medline

Ginhoux F, Greter M, Leboeuf M, Nandi S, See P, Gokhan S, Mehler MF, Conway SJ, Ng LG, Stanley ER, Samokhvalov IM, Merad M (2010) Fate mapping analysis reveals that adult microglia derive from primitive macrophages. Science 330:841-845. CrossRef Medline

Grubb MS, Burrone J (2010) Activity-dependent relocation of the axon initial segment fine-tunes neuronal excitability. Nature 465:1070-1074. CrossRef

Hanisch UK (2013) Functional diversity of microglia - how heterogeneous are they to begin with? Front Cell Neurosci 7:65. CrossRef Medline

Hanisch UK, Kettenmann H (2007) Microglia: active sensor and versatile effector cells in the normal and pathologic brain. Nat Neurosci 10:13871394. CrossRef Medline

Hedstrom KL, Xu X, Ogawa Y, Frischknecht R, Seidenbecher CI, Shrager P, Rasband MN (2007) Neurofascin assembles a specialized extracellular matrix at the axon initial segment. J Cell Biol 178:875-886. CrossRef Medline

Hinman JD, Rasband MN, Carmichael ST (2013) Remodeling of the axon initial segment after focal cortical and white matter stroke. Stroke 44:182189. CrossRef Medline

Ho TS, Zollinger DR, Chang KJ, Mingxuan X, Cooper EC, Stankewich MC, Bennett V, Rasband MN (2014) A heirarchy of ankyrin-spectrin complexes clusters sodium channels at nodes of Ranvier. Nat Neurosci 17: 1664-1672. CrossRef

Hoshiko M, Arnoux I, Avignone E, Yamamoto N, Audinat E (2012) Deficiency of the microglial receptor CX3CR1 impairs postnatal functional development of thalamocortical synapses in the barrel cortex. J Neurosci 32:15106-15111. CrossRef Medline

Hristova M, Cuthill D, Zbarsky V, Acosta-Saltos A, Wallace A, Blight K, Buckley SM, Peebles D, Heuer H, Waddington SN, Raivich G (2010) Activation and deactivation of periventricular white matter phagocytes during postnatal mouse development. Glia 58:11-28. CrossRef Medline

Iwakura A, Uchigashima M, Miyazaki T, Yamasaki M, Watanabe M (2012) Lack of molecular-anatomical evidence for GABAergic influence on axon initial segment of cerebellar Purkinje cells by the pinceau formation. J Neurosci 32:9438-9448. CrossRef Medline

Jung S, Aliberti J, Graemmel P, Sunshine MJ, Kreutzberg GW, Sher A, Littman DR (2000) Analysis of fractalkine receptor CX(3)CR1 function by targeted deletion and green fluorescent protein reporter gene insertion. Mol Cell Biol 20:4106-4114. CrossRef Medline

Kettenmann H, Ransom BR (2005) Neuroglia. New York: Oxford UP.

Kole MH, Stuart GJ (2012) Signal processing in the axon initial segment. Neuron 73:235-247. CrossRef Medline

Kreutzberg GW (1996) Microglia: a sensor for pathological events in the CNS. Trends Neurosci 19:312-318. CrossRef Medline

Kuba H, Oichi Y, Ohmori H (2010) Presynaptic activity regulates $\mathrm{Na}(+)$ channel distribution at the axon initial segment. Nature 465:1075-1078. CrossRef

Lawson LJ, Perry VH, Dri P, Bordon S (1990) Heterogeneity in the distribution and morphology of microglia in the normal adult mouse brain. Neuroscience 39:151-170. CrossRef Medline 
Li Y, Du XF, Liu CS, Wen ZL, DU JL (2012) Reciprocal regulation between resting microglial dynamics and neuronal activity in vivo. Dev Cell 23: 1189-1202. CrossRef Medline

Merchant H, de Lafuente V, Peña-OrtegaF, Larriva-Sahd J (2012) Functional impact of interneuronal inhibition in the cerebral cortex of behaving animals. Prog Neurobiol 99:163-178. CrossRef Medline

Newell EW, Schlichter LC (2005) Integration of $\mathrm{K}+$ and Cl- currents regulate steady-state and dynamic membrane potentials in cultured rat microglia. J Physiol 567:869-890. CrossRef Medline

Nimmerjahn A, Kirchhoff F, Helmchen F (2005) Resting microglial cells are highly dynamic surveillants of brain parenchyma in vivo. Science 308: 1314-1318. CrossRef Medline

Ogawa Y, Horresh I, Trimmer JS, Bredt DS, Peles E, Rasband MN (2008) Postsynaptic density-93 clusters Kv1 channels at axon initial segments independently of Caspr2. J Neurosci 28:5731-5739. CrossRef Medline

Ogawa Y, Oses-Prieto J, Kim MY, Horresh I, Peles E, Burlingame AL, Trimmer JS, Meijer D, Rasband MN (2010) ADAM22, a Kv1 channelinteracting protein, recruits membrane-associated guanylate kinases to juxtaparanodes of myelinated axons. J Neurosci 30:1038-1048. CrossRef Medline

Pannell M, Szulzewsky F, Matyash V, Wolf SA, Kettenmann H (2014) The subpopulation of microglia sensitive to neurotransmitters/neurohormones is modulated by stimulation with LPS, interferon-gamma, and IL-4. Glia 62:667-679. CrossRef Medline

Paolicelli RC, Bolasco G, Pagani F, Maggi L, Scianni M, Panzanelli P, Giustetto M, Ferreira TA, Guiducci E, Dumas L, Ragozzino D, Gross CT (2011) Synaptic pruning by microglia is necessary for normal brain development. Science 333:1456-1458. CrossRef Medline

Parkhurst CN, Yang G, Ninan I, Savas JN, Yates JR 3rd, Lafaille JJ, Hempstead BL, Littman DR, Gan WB (2013) Microglia promote learning-dependent synapse formation through brain-derived neurotrophic factor. Cell 155: 1597-1609. CrossRef Medline

Paxinos G, Watson W (2007) The rat brain in stereotaxic coordinates, Ed 4. Boston: Academic.

RansohoffRM, Perry VH (2009) Microglial physiology: unique stimuli, specialized responses. Annu Rev Immunol 27:119-145. CrossRef Medline

Robertson CS, Garcia R, Gaddam SS, Grill RJ, Cerami Hand C, Tian TS, Hannay HJ (2013) Treatment of mild traumatic brain injury with an erythropoietin-mimetic peptide. J Neurotrauma 30:765-774. CrossRef Medline

Rogers JT, Morganti JM, Bachstetter AD, Hudson CE, Peters MM, Grimmig BA, Weeber EJ, Bickford PC, Gemma C (2011) CX3CR1 deficiency leads to impairment of hippocampal cognitive function and synaptic plasticity. J Neurosci 31:16241-16250. CrossRef Medline

Rusnakova V, Honsa P, Dzamba D, Ståhlberg A, Kubista M, Anderova M (2013) Heterogeneity of astrocytes: from development to injury-single cell gene expression. PLoS One 8:e69734. CrossRef Medline
Schafer DP, Stevens B (2013) Phagocytic glial cells: sculpting synaptic circuits in the developing nervous system. Curr Opin Neurobiol 23:10341040. CrossRef Medline

Schafer DP, Jha S, Liu F, Akella T, McCullough LD, Rasband MN (2009) Disruption of the axon initial segment cytoskeleton is a new mechanism for neuronal injury. J Neurosci 29:13242-13254. CrossRef Medline

Schafer DP, Lehrman EK, Kautzman AG, Koyama R, Mardinly AR, Yamasaki R, Ransohoff RM, Greenberg ME, Barres BA, Stevens B (2012) Microglia sculpt postnatal neural circuits in an activity and complement-dependent manner. Neuron 74:691-705. CrossRef Medline

Sierra A, Encinas JM, Deudero JJ, Chancey JH, Enikolopov G, OverstreetWadiche LS, Tsirka SE, Maletic-Savatic M (2010) Microglia shape adult hippocampal neurogenesis through apoptosis-coupled phagocytosis. Cell Stem Cell 7:483-495. CrossRef Medline

Susuki K, Chang KJ, Zollinger DR, Liu Y, Ogawa Y, Eshed-Eisenbach Y, Dours-Zimmermann MT, Oses-Prieto JA, Burlingame AL, Seidenbecher CI, Zimmermann DR, Oohashi T, Peles E, Rasband MN (2013) Three mechanisms assemble central nervous system nodes of Ranvier. Neuron 78:469-482. CrossRef Medline

Szabadics J, Varga C, Molnár G, Oláh S, Barzó P, Tamás G (2006) Excitatory effect of GABAergic axo-axonic cells in cortical microcircuits. Science 311:233-235. CrossRef Medline

Tremblay ME, Lowery RL, Majewska AK (2010) Microglial interactions with synapses are modulated by visual experience. PLoS Biol 8:e1000527. CrossRef Medline

Ueno M, Fujita Y, Tanaka T, Nakamura Y, Kikuta J, Ishii M, Yamashita T (2013) Layer V cortical neurons require microglial support for survival during postnatal development. Nat Neurosci 16:543-551. CrossRef Medline

Wake J, Moorhouse AJ, Jinno S, Kohsaka S, Nabekura J (2009) Resting microglia directly monitor the functional state of synapses in vivo and determine the fate of ischemic terminals. J Neurosci 29:3974-3980. CrossRef Medline

Woodruff AR, McGarry LM, Vogels TP, Inan M, Anderson SA, Yuste R (2011) State-dependent function of neocortical chandelier cells. J Neurosci 31:17872-17886. CrossRef Medline

Yang Y, Lacas-Gervais S, Morest DK, Solimena M, Rasband MN (2004) BIV spectrins are essential for membrane stability and the molecular organization of nodes of Ranvier. J Neurosci 24:7230-7240. CrossRef Medline

Zhan Y, Paolicelli RC, Sforazzini F, Weinhard L, Bolasco G, Pagani F,Vyssotski AL, Bifone A, Gozzi A, Ragozzino D, Gross CT (2014) Deficient neuron-microglia signaling results in impaired functional brain connectivity and social behavior. Nat Neurosci 17:400-4006. CrossRef Medline

Zhang Y, Barres BA (2010) Astrocyte heterogeneity: an underappreciated topic in neurobiology. Curr Opin Neurobiol 20:588-594. CrossRef Medline 